\title{
Oração ao Paraninfo
}

JosÉ Olinto de Andrade Junqueira

Exmo. Snr. Diretor

Egregia Congregação

Minhas Senhoras e Senhorinhas

Meus Senhores

Meus colegas

Dr. Waldemar Ferreira

“. Nihil novum...

.. ce n'est qu'en montant sur les épaules des autres que nous pouvons voir d'un peu loin..."

Transcorre neste ambiente, sempre procurado como ponto de irradiação das grandes iniciativas ou das questões cientificas que visam diretamente o interêsse da coletividade, mais uma comemoração desta Casa, em que nós outros, por algumas horas, nos detemos juntos em atitude retrospetiva "debruçados na ampla balaustrada do passado" que se projeta no campo longinquo do futuro; é uma parada momentanea, é um instante de meditação reflexa; é a ocasião oportuna que se nos oferece para tomar uma atitude, escolhendo uma diretriz. 
De fato, rememorar, passar em vista os momentos de derrotas e vitórias, constatar a realidade com suas leis sábias de progresso e decadencia, é agir com probabilidade de êxito. E nos ensina o metodo cientifico que é observando o passado, comparando-o com o presente, que podemos solucionar os problemas vigentes e nos acautelar dos imprevistos futuros.

Tarefa ardua e de responsabilidade, afigura-se-me, esta incumbencia de meus colegas; ardua, porque a situação mundial em seus aspectos polimorficos nunca esteve em condições tão precárias, a ponto de proporcionar um diagnostico seguro da atualidade; de responsabilidade, porque envolve as tradições luminosas da Academia, onde vozes autorizadas e competentes se fizeram ouvir interpretando o sentir das gerações que nos precederam.

No entanto, urge tomar uma atitude e com resolução firme procurar fazer uma análise minuciosa de todas as questões politico-sociais que ora se degladiam, se mesclam, se destróem, e trazem ao ambiente atual a instabilidade que o carateriza, sendo classificado como periodo de transição, passagem para um novo standard de vida, ou como querem outros uma nova concepção da vida.

Vivemos a hora trepidante da máquina, e todas as questões com os seus resultados imediatos e correlatos, seguem o mesmo ritmo, a mesma velocidade, e de um jacto nos apresentam a complexidade e grandiosidade dos problemas atuais. Como resolvê-los? Aplicando o passado ao presente? Seguindo a rotina? Improvisando soluções cerebrinas?

Com estas interrogações, nesta quadra de ceticismo, aparecem as novas gerações, com a incumbencia de minorar os efeitos desastrosos dos erros, dos principios, dos sistemas!

A responsabilidade da juventude, torna-se cada vez mais necessaria e imperiosa; atesta-o o papel revolucionaric que 
ela exerce hodiernamente em todas as renovações. (1) A ruptura com o passado que se mostra estreito e diminuto para compreender e ditar soluções á magnitude e rapidez dos problemas que se apresentam; partem-se as fortes amarras da tradição e da história e constata-se a improvisação das mais variegadas questões relativas a coexistencia humana e ao govêrno dos povos.

Efetivamente, o que nos é dado observar é o estado caótico, convulsionado, transitorio; alguns; sonhadores utopicos, crentes fervorosos do grande poder realizador da creatura, enxergam satisfeitos os derradeiros esforços do capitalismo que se suicida e divagam sôbre um novo estado de cousas, que tem no evolucionismo a explicação filosofica dos dias vindouros.

Mas como, onde está o seculo otimista? Esta pergunta não pode ser compreendida por nossa geração, quer no campo teorico dos principios, quer na aplicação objetiva dos mesmos.

De há muito não se ouve a grita orgulhosa e vasia de igualdade liberdade e fraternidade; já vão longe aqueles dias bonançosos, epoca entusiasmada da ciência onipotente; o otimismo burguês não prognostíca entusiasmo nem discursa prazenteiro a respeito da excelencia do regime, que se dizia ereto em bases graniticas. A facilidade com que o homem resolvia os maiors segredos da natureza, até então, impenetraveis ou ameaçadores; a rapidez com que a creatura ganhava espaços, encurtando distancias; a abundancia que já se constatava, anunciando dias de bonança; enfim o dominio crescente do homem sôbre a natureza, embalava o sonho dos sociologos - convictos de uma proxima vitória, integral, perfeita, completa!

Nesta escalada gigantesca, o homem operou um verdadeiro milagre; com o uso intensivo e extensivo da máquina,

(1) V. George Roux - L'Italie Fasciste. 
que não se adapta á organização vigente, trouxe consigo êste sequito numeroso de disturbios e cataclismas !

Se ontem os principios liberais individualistas construiam um regime que unificava todas as opiniões, solucionava todas as controversias e ganhava aplausos de todos os pensadores, já não o podem pretender nos dias terroristas que atravessamos, onde o amanhã se nos apresenta como uma dolorosa incognita, epoca de constatação experimental do resultado nefasto de tão decantados principios, agora indefensaveis ante a mudança radical do ambiente em que operam.

Ontem, a necessidade de proteção ao indivíduo, cercando-o de direitos e garantias, com a adoção de principios trabalhosamente conquistados, que se impuzeram paulatinamente pelos excessos da nobreza.

Hoje já se conclúi que o individualismo liberal estacionou no ponto em que partira, desmentindo todas as previsões; (2); trouxe o agravamento espantoso em todas as questões politicas e economicas, aparecendo naquelas como oligarquia, e nestas como a tiranica e injusta ditadura do capital; tiranica, porque esmaga a grande maioria trabalhadora, valendo-se de sofismas e subterfugios; injusta, porque chega ao aniquilamento da personalidade humana, sujeita ás oscilações da lei da oferta e da procura, aparecendo na história cenas ineditas de sofrimentos, e que se revelam assustadoramente nas grandes aglomerações urbanistas, onde o pauperismo se avoluma numa progressão constante!

Para obviar tantos inconvenientes, levado pelo louvavel intuito de remediar a situação que se mostra insustentavel, começou a intervenção governamental, tímida a princípio, aos poucos mais audaciosa, tateante sempre, atacando pontos accidentais, olvidando a verdadeira causa do mal estar - da crise - se é que esta palavra pode resumir todos os efeitos catastroficos que observamos, na triplice manifestação do "homo sapiens": espiritual, política e economica.

(2) V. A 4." Humanidade, de Plinio Salgado. 
A explicação do travamento, da estagnação ou rebaixamento de todas as atividades economicas, começado no "crack" de Nova-York em 29 e repercutido gravosamente em todas as bolsas e mercados, encontra-se sintetizada grossomodo, na seguinte fórma: não há estabilidade politica, porque não há estabilidade economica; não há estabilidade economica porque não há estabilidade financeira. Esta se origina da falha do regime: o dole representa sem dúvida, em todos os paises industrializados capitalistas, após os gastos nababescos do militarismo, a maior contribuição no esfacelamento do equilibrio orçamentario; e na economia liberal é bem conhecido o papel preponderante e orientador dêste fator, base influente da confiança na reciprocidade das relações comerciais, fator psicologico que informa e dirige todo emprêgo de capital, mormente nas grandes sociedades anonimas para onde é canalizado o maior lastro metalico, seguindo o principio da concentração do capital. (3).

Neste ponto deparamos com duas tendencias antagônicas ao procurar o tratamento especifico a ser ministrado com intuito de tonificar o Estado moderno, na exata compreensão hierarquica de seus elementos constitutivos: Estado, sociedade, e indivíduo.

A primeira, corrente, conservadora, carateriza-se propriamente por um socialismo de Estado, em que, mantidos os mesmos princípios, procura-se obviar os males supervenientes pela intervenção governamental; não apresenta uma seqüencia de princípios solidos, harmonicos, concatenados; improviza soluções empíricas, medidas protelatórias, em satisfação aos reclamos das massas, já concientes de sua força fisica. Funda-se geralmente em duas ordens de argumentos, conforme se se trate de país ainda no periodo embrionario da máquina, ou naquele em que esta trouxe as suas últimas conclusões.

(3) V. La crise Britannique au XX Siècle, de ANdré Srgfried. 
No primeiro caso, parece a muitos que se deva atribuir á luta aduaneira, ao insulämento econômico dos países, á exclusiva responsabilidade no retraímento progressivo das transações. No entanto o fenômeno é bem mais complexo e revela causas remotas, princípios já olvidados. Essa atitude de belicosidade econômica, é antes ditada como última medida de salvação, como a mais perfeita legítima defesa, de que a Inglaterra e os Estados Unidos, nos fornecem o mais frisante exemplo.

Tal procedimento, sem dúvida, agrava sobremaneira o reatamento das relações pacifistas trazendo um desequilibrio ainda maior pela introdução de um novo fator que transtorna radicalmente os princípios basicos da livre concorrência.

E' que a máquina deixando de ser um previlegio europeu ou norte-americano, quer pelo descobrimento do carvão e petroleo em outros territorios, quer pela transformação maravilhosa trazida pela eletricidade superando todas as vantagens que seus antecessores imprimiam á maquino-fatura, estende-se rapidamente por todos os Continentes, que surgem como outros tantos rivais, exigindo mercados para colocação de seus produtos.

A solução do problema deve ser encontrada intra-muros; dentro das respetivas fronteiras; já não impressiona o sofisma de todos os dias por dizer que não há super-produção mas sim sub-consumo; tão pouco não se resolve o impasse atribuindo excessiva preponderancia a determinado capítulo da Economia Política; o momento não comporta paliativos; exige rumos esclarecidos, impulsionados por uma ação constante e metodica.

No segundo caso, nos países industrializados, adicionase mais um argumento: o manifesto desequilibrio que ora se observa será paulatinamente corrigido pela atividade social do Estado. Tais conquistas, consubstanciadas em direitos e garantias, iriam aumentar a galeria, já faustosamente povoada da Declaração dos Direitos do Homem, tal como 
se realiza na Constituição de Weimar e mais recentemente na da Espanha. (4)

$O$ abandono isolado do individualismo liberal, tal como vem se realizando na Alemanha, mostra concludentemente a precariedade de seus resultados; a taxação crescente das riquezas oligarquicas não fornece subsidios abundantes para atender a todos os compromissos, e tambem porque no regime de voto estritamente político, as minorias encontram sempre processos faceis de se isentarem dêsse onus, recaindo na massa super-tributada os maiores encargos do orçamento. Em tal organização a máquina continua a sua faina destruidora, contribuindo diretamente para o chomage.

Surge então outra corrente, dita revolucionária; investiga a solução do problema, seguindo um processo lógico, ao procurar remover as causas, abandonando princípios erroneos.

A multiplicidade de doutrinas e a sua consequente proliferação ganhando adeptos, não só no terreno especulativo das idéas, como tambem em suas eficientes realizações no tempo e no espaço, estão a patentear, senão a veracidade integral de seus princípios, ao menos a manifestação concreta no repudiar sistemas arcaicos e anacrônicos.

A' parte o excesso condenavel que reponta em algumas dessas teorias, como seja a ditadura monoclassica do sovietismo, ou o poder centralizador e absorvente do fascismo, tanto o corporativismo como o socialismo em suas várias modalidades, atinam com argucia e sabedoria no estabelecer e remover principios antiquados adotando a tecnica capitalista, com a extensão de seus beneficios a todos os membros da coletividade.

$O$ que há de comum e verdadeiro em todos esses sistemas reformadores, é justamente o nexo que os irmana e os frutifica; todos estão acordes em condenar a dissociação econômica, (5), onde patrões e operarios se defrontam nu-

(4) V. Comentarios a Constituição de Hespanha, de Victor Viana.

(5) V. O Problema da Burguesia, de Tristão de Athayde. 
ma relação de desigualdade, que flutua ao sabor das circunstâncias; todos subordinam as várias soluções concretas e particulares e uma concepção filosofica, abandonando por completo o casualismo liberal, amorfo, ao se orientar por rumos contrários e sinuosos de acôrdo com a roleta do voto político.

Justamente neste momento critico, em que se conflagram princípios antagônicos, experimenta a nossa extremecida terra, a periodicidade das revoluções; e se nas primeiras tudo se resume em uma passageira agitação' de quarteis, sem maiores repercussões de causalidade nos principios revolucionarios, já nas duas últimas, o fenomeno subversivo se presta a considerações de outra ordem, a ponto de permitir o estabelecimento de princípios inadaptaveis e que transtornam visceralmente a nossa organização política e econômica.

Quais sejam? Como removê-los?

Pululam, então, os princípios exclusivistas e sectarios, a reinvindicar uma solução simplista e radical aos nossos males congênitos; seja na crítica incessante dos princípios idealistas de nossa Magna Carta, seja na apreciação dos nossos valores raciais, seja no definir e harmonizar a estrutura fisica do território com o elemento etnico que o vitaliza e transforma.

Alguem já disse e muito a propósito, que vivemos na terra dos paradoxos. Mais uma vez temos que aceitar, a verdade rude desse enunciado. Ainda nos debatemos com todas as dificuldades e obstaculos no orientar os primeiros passos da máquina, e já estamos sofrendo as conseqüencias funestas da superprodução.

(6) Direito Constitucional, de Pontes de Miranda. 
Encontrando os mesmos efeitos, procura essa recente floração de apressados sociologos, referílos á mesma causa; a seguindo tal orientação, quer atribuir ao latifundio agrario (mais de fantasia que da realidade) os mesmos defeitos que se encontram na concentração capitalista. Só a ignorancia completa do nosso interland, ondẹ a suprema dificuldade, não é adquirir a terra, mas sim manter-se nela, pode engendrar planos utopicos, que falharão certamente, por não contarem com o apoio imediato e direto da iniciativa particular, neste Brasil imenso e despovoado, em que tudo está por fazer, e que estacionará irremediavelmente neste marasmo se permanecer nesta atitude messiânica, aguardando uma hipotética intervenção do Poder Público em todas as manifestações da sociabilidade brasileira.

Em verdade, se alhures o problema capital se resume em evitar as revoluções sociais na harmonização das classes, aqui ainda estamos nos primordios da evolução economica, onde se observam as migrações sociais, sem a delimitação férrea dos interêsses intransponiveis.

Então, a que atribuir a manifestação morbida das ideologias revolucionarias? Os erros e falhas das nossas instituições justificavam essas rebeliões, sempre funestas ao Organismo Nacional, já fortemente combalido?

A 1. ${ }^{\text {a }}$ revolução nacional que teve seu desfecho em $\mathrm{Ou}-$ tubro de 1930 , como faz notar muito a proposito um de nossos investigadores sociais, (7), se recebeu o beneplácito da maioria pensante da nação, que pedia reformas urgentes, não passou em última análise da explosão violenta de todos os regionalismos: Estes, habilidosamente, articulados, manejados com astúcia pela demagogia oposicionista", já côncia de sua superioridade civica", encontraram na crise cafeeira, que repercutiu desastrosamente em toda a economia nacional, o mais entusiasmado e poderoso dos aliados.

(7) V. Desordem, de Virainio de Santa Rosa. 
Sem atribuir exagerada preponderância ao fator econômico, pois na gênese deste estado de cousas, colaboraram eficazmente os desatinos políticos, não se pode olvidar, que do restabelecimento da atividade econômica depende a pacificação dos regionalismos descontentes que surgem meste periodo de desordem, pondo em perigo assustador a Unidade Nacional.

Neste ponto, sei perfeitamente que são numerosos e intransigentes os defensores do desmembramento, que conta em nossa dadivosa Piratininga com mentores entusiastas. Como observa, criteriosamente, a opinião contrária, tornamse improcedentes todos os argumentos apresentados, em face de duas razões capitais; de um lado, o separatismo renegaria todo esforço hercúleo da audacia bandeirante que dilatou as fronteiras, conquistando "êsse gigante que tem a cabeça recostada nos Andes, e os braços apertando a imensidão Oceanica"; de outro lado, o argumento da superioridade econômica, (8), em que São Paulo, por ter o produto de maior densidade econômica, poderia se organizar soberanamente, é o mais aleatorio possivel. Deve-se ter em mente, que o centro de gravidade econômica brasileira, deslocou-se sucessivamente de Pernambuco para a Amazonia, e desta para São Paulo. A borracha substituiu com vantagem a perda do assucar, e o café superou todos os benefícios da "hevea brasiliensis" Qual o sucessor da preciosa rubiacea?

A idéa nativista, toma vulto nestes momentos de transição e reformas, onde a errônea diretriz do Govêrno Provisorio contribúi diretamente alimentando a efervescencia dessa ideia sugestiva. Querendo centralizar toda a vida administrativa do País, fomenta ela propria êsse sentimento de protesto e de rebeldia; querendo controlar todos os regionalismos que the deram origem, por meio de um poder pessoal e discricionario, realiza a maior desigualdade no tratar os elementos constitutivos da nacionalidade. Essa a

(8) V. Confederação ou Separação, de Alfredo Ellis Junior. 
causa imediata e direta do descontentamento generalizado. Essa, a explicação que salta aos olhos para o movimento de 9 de julho; foi o brado de alerta, o protesto sanguinolento, em que todo São Paulo se levantou coêso, assombroso, numa arrancada que o imortaliza, já na sua prodigiosa improvisação guerreira, já na sua resistencia titanica.

Não quero analisar detalhadamente êste episodio que ainda está vivo na memória de todos nós; mas cometeria uma grande injustiça para com êste sagrado Templo de ensinamentos civicos, se não registrasse o papel saliente da mocidade bandeirante, que soube cumprir dignamente o seu dever; não só no periodo preparatorio em memoraveis propagandas, como tambem na fase rubra do esfôrço e do desprendimento ao emprestar o seu integral apoio, postando-se nas fileiras avançadas de todas as frentes.

As revoluções nos fornecem subsidios abundantes para estudos, fazendo surgir á tona manifestações palpaveis de erros latentes; na política põem em relevo mais uma vez o desequilibrio dos Estados na Federação em que não se adotou nenhum critério racional na determinação das circunscrições autônomas; (9) na economia, evidencia-se o sacrificio progressivo do interêsse coletivo por um protecionismo alfandegario a beneficiar as oligarquias situadas nos centros populosos; na pedagogia, já se constata o rebaixamento cultural das elites, fruto das mutações de planos e reformas. Todos esses fatores adicionados, nos levaram á periodicidade das revoluções; o aparecimento subseqüente de outros, como seja a intervenção dos militares na política, como tambem, o ambiente de desconfiança inerente a todo regime de ditadura, nos apresentam novos entrechoques de idéias e opiniões. Só o regime legal, expurgado de suas excrescencias, sábiamente orientado pelas modernas correntes que visam a racionalização do Poder pondo em equilibrio estavel as forças vivas da nação, poderá restabelecer o apa-

(9) V. Brasil Desunido, de Sud Menucci. 
ziguamento das conciencias, sem o qual será vã toda tentativa de Reconstrucção Nacional.

Que as minhas últimas palavras sejam de despedidas e de agradecimentos. Âo transpormos essas venerandas arcadas, sentimos bem de perto a mágoa que assalta a nossa imaginação de moços, por deixar o convivio confortador dos colegas que aqui ficam e que sempre nos alegraram com seu cavalheirismo; e daqueles que se foram, vítimas de seu idealismo sadio, eternamente relembrados nas tradições desta Casa, conforta-nos a recordação imperecivel desses heróis, cuja simples invocação desfralda uma bandeira de exemplos e de patriotismo !

Aos nossos idolatrados Mestres, que nos guiaram em todos os labírintos da ciência juridica com maestria e erudição os nossos sinceros agradecimentos.

Ao nosso ilustre paraninfo, Dr. Waldemar Ferreira, aqui condignamente representado, intérprete da nossa simpatia, como um de nossos mais provectos jurisconsultos e que na administração pública deu sobejas demonstrações, como espirito clarividente e realizador, a gratidão sincera de seus afilhados, conferindo-nos a honra de sua aquiescencia, para maior brilho desta solenidade.

Finalmente, fazendo minhas as palavras de um colega (10) :

"E de ti, velha Faculdade, templo mais que secular, onde a oração é o trabalho pelo futuro da Patria, nós nos despedimos com a mais profunda emoção, neste instante em que te deixamos, mais do que nunca envolta na tua gloria centenária, atenta na tua empresa nacionalista ciente da

(10) V. Discurso de Orador da turma de Garibaldi de Melwo Carvalho. 
tua sublime responsabilidade. Deixamos contigo muito de nós e de nossa vida e conosco levamos, tambem, muito da tua estranha religiosidade e da tua personalidade propria. $\mathrm{E}$ que fique sempre conosco a memória bendita do teu nome, glorificado e excelso, como um incentivo para as vicissitudes da vida. E que fique sempre contigo, com teus mestres, e com a tua eterna mocidade, a certeza de que, lá fora, onde se agita o turbilhão humano, saberemos honrar os compromissos que, pela cerimonia de hoje, assumimos deante de ti, da Patria e da conciencia."

Tenho dito. 